\title{
The Individual vs Group Assessment of the Writing: A Study in Pupils with High School Performance D-F Primary
}

\author{
Styliani Xanthi \\ Department of Humanity, Hellenic Open University, Athens, Greece
}

Email address:

sxanthi@sch.gr

\section{To cite this article:}

Styliani Xanthi. The Individual vs Group Assessment of the Writing: A Study in Pupils with High School Performance D-F Primary. Education Journal. Vol. 8, No. 5, 2019, pp. 232-238. doi: 10.11648/j.edu.20190805.18

Received: August 5, 2019; Accepted: August 23, 2019; Published: September 5, 2019

\begin{abstract}
Assessment is a systematic process through which we can find what pupils know and what they can do individually and as a group concerning their optimal development and the curriculum objectives. In the present study, skills, and knowledge of the writing evaluated with informal tests based on the curriculum to pupils with high school performance, aged 9-12. The aim was to explore the performance of pupils when they tested individually and when they tested as a group. For this purpose, 22 pupils tested as individuals and as a group tested 34 pupils. Such investigation should give us the opportunity for useful conclusions for appropriate assessment methods and means of collecting information at language skills related to the processing and production of written language in the last grades of primary school. Findings indicate that the assessment process, individually vs. group, seems to have influenced pupils' performance significantly. The pupils who tested as a group had lower performance in all tests. These findings are consistent with the position that the individual tested focuses better on individual skills and enables the examiner to gain a more valid image for the behavior of the pupils.
\end{abstract}

Keywords: Individual Assessment, Group Assessment, Writing, High School Performance

\section{Introduction}

The assessment is a systematic process through which we find what students know and what they can do individually and as a group, related to their optimal development and the curriculum goals [9]. The success of an assessment is determined to a great extent by choosing the appropriate assessment methods, and the means of collecting information.

The assessment can be either individual or group depending on the number of subjects that tested at a time. Individual assessment aims are to identify the pupils' skills, and the weaknesses related to the content of the curriculum individually. The objective of the group assessment is to evaluate the progress of the whole class about the curriculum [19]. Group assessment based on the person's independent response behavior and the examiners did not intervene immediately. Instructions reduced, and the clarifications by the examiner differentiated accordingly. There is no possibility of direct personal contact between the examiner and the examined. In the group test, the pupils should develop, with less help from the examiner, a well written and oral understanding of the instructions. The individual assessment focuses more on skills individually. It enables the examiner to gain a more valid image of the behavior of the subject [2].

Tools of assessment can be informal, unofficially or weighted, formally, officially. The official tools are more objectives and use tests based on constant psychometric principles in the same way across all subjects. Informal tools are unofficial, they can be immediate, and their writing is quick because they based on the curriculum. Also, they provide more flexibility compared to the rigorousness of weighted tests [22]. The usefulness of atypical tests is high, without however replacing weighted tools. The informal assessment is more enjoy great popularity to teachers because it satisfies their need to evaluate the pupil within the school and is based on the curriculum [21]. It can be oriented for assessment at both individually and as a group [1].

The inadequacy of many weighted tests and their removal from the classroom's daily routine, as well as the inability to formulate results in an intervention program, reveal the teacher's importance in the assessment process of a pupil [15]. Thus, the curriculum-based assessment has emerged in a viable and psychometrically effective perspective against the 
weakness of the weighted tests to describe the deficits and abilities of the pupils in various cognitive subjects effectively [4]. However, it should not overlook that each test has a limited degree of reliability, smaller or larger. Even if all the conditions for designing and testing the content of the assessment tests meet, the resulting information should not be overestimated [11]. The assessment, even if well-designed, involves some limitations, such as the possibility of error. It should not forget that the assessment offers a sample of a performance that can be different from its real image [14].

A central element of the educational process is the appreciation of the linguistic difficulties in writing. It concerns the functional assessment of the linguistic and postlinguistic skills - oral and written- as well as the cognitive and the metacognitive elements of speech content [18]. School skills as the production and processing of written language included in mainstream schooling, and they are an objective of the curriculum for all levels of education [17]. It is a complex and multilevel process that is necessary to combine cognitive and meta-cognitive skills, linguistic and post-linguistic knowledge, visual-kinetic skills, and social and cultural knowledge [20]. The ability to produce and process the written word develops gradually. It is considered more automated after the fourth grade of primary school. The syntax and semantic skills are now at a similar level of development. The children make longer sentences with sophisticated vocabulary and conceptual content. They write faster and more efficiently, and they have incorporated and automated the rule systems. They organize what they want to write consciously, and they begin to read their written texts and evaluate them [12].

In the curriculum, the students are encouraged to finish the elementary school with the ability to write spelling using grammar rules. Transform texts into different kinds for a different purpose, and convey complex ideas with extended vocabulary effectively. Distinguish the meaning of a word based on its origin, affinity or contrast, their metaphorical use, and the context, and give empirical word definitions. To become familiar with pluralism is used the etymological elements of words. Categorize them semantically and guess their significance with the help of the context. Recognize the parts of a sentence and the linguistic parts, sometimes individually and sometimes with their syntactic role within the sentence, as well as the components of a paragraph and carry out analyzes and reconstructions [25].

The paper presented in this article proposes the assessment with informal tests about the curriculum. The atypical tests would provide more information about the language skills of children because they based on qualitative criteria. They designed to describe performance rather than compared with norms. Also, such a form of assessment can be given both individually and as a group.

The main objective of the research was to evaluate a range of language skills related to the processing and production of written in pupils with high school performance in the last grades of primary school. Also, the aim was to investigate whether the type of assessment, individual vs. group, differentiates pupil's performance.

\section{Method}

\subsection{Participants}

Exclude potential constraints stemming from grand individual differences in pupils' abilities, 56 pupils with high school performance selected as a sample. The specific pupils, 29 girls and 27 boys, 4th grade $(\mathrm{N}=18), 5$ th grade $(\mathrm{N}=14)$ and 6 th grade $(\mathrm{N}=24)$, were indicted by the class teachers with criterion the high response to the objectives of the class curriculum in all courses.

\subsection{Instruments}

The research tool chosen for this study was a test set that combines tests of psychometric criteria of language proficiency with informal tests and free text-writing. The most tests are activities in the school books of the last three grades of the Primary School [24]. As a model, both theoretically and functionally, were used the Diagnostic Investigation Tool for Difficulties in the Writing of Pupils in C-F grade of Primary School [16] and the L-a-T-o [23].

In the test 1 was evaluated the ability of pupils to use the punctuation points correctly. Specifically, their internalization and the application of the punctuation rules to determine the sentences and the types of them. Pupils put 18 punctuation marks in the dialogue. They had to check both the meaning of each sentence and the dialogue meaning.

The knowledge of the words function syntactically and the structure of a simple and compound sentence, with active or passive structure, evaluated by two tests. In the test 2 pupils had to make two sentences, one with active and one with passive structure, with specific words. In the test 3 pupils put together two pairs of sentences, main/subordinate, and they make compound sentences. There were opportunities for syntactic errors in the subject, in the verb, in the object of simple sentences or determination. Also, there were opportunities for mistakes in the link of compound sentences.

Recognition of various morphological types of words was tested by filling gaps in the text. The pupils had to find synonyms and opposites words. Also, they had to put the words in their correct declension. Furthermore, they had to use the production and synthesis relationships that exist between them. In the test 4 pupils had to change the words in different grammatical types or put them in their correct declension contextually. In the test 5 pupils had to fill a similar, opposite or compound word related to the word of parentheses. They had to understand the meaning of the text. There were the possibilities by inconsistent use of the time, the person, and the number verb. Also, there were the probabilities by inconsistent use in gender, the number, and the case of nouns, adjectives, and pronouns. Furthermore, pupils could make errors in the synonyms or the opposites.

In the test 6 were tested the language experience, and the understanding of special meanings like the knowledge of idioms, proverbs, and comparisons. The pupils were asked to 
complete the second part of two proverbs, of two simulations, and two metaphors. There were opportunities for mistakes in the type of metaphor or the meaning of the phrase, literal or metaphorical.

In the test 7 were tested the knowledge of the meaning of a word. Also, were tested the ability to interpret multiple meanings of them. The pupils had to find two related words of the words: walking, healthy, space, height. It could have been a synonym, a distinctive feature, a general meaning, a relative grammar type, or a metaphorical meaning. There was the possibility of using an irrelevant word, either a word with a syntactic relation.

In the test 8 tested the understanding meaning of words with simple formal definitions. The pupils had to define the meaning of four words: hat, umbrella, horse, thief [3]. The pupils may fail partially using a vague or less relevant synonym, a secondary meaning, the successful but specific use of the word without any further clarification. Furthermore, there was the possibility of failing by saying a common phrase that contained the word but did not show a real understanding of its meaning even after a clarifying question.

In the test 9 tested the ability to organize perceiving the sequence of events. Also, was tested the writing ability. The pupils had to identify the right pair of sentences, and the link which they linked. Then they had to put them in time order and to make a paragraph adding their words or their phrases.

The writing ability, as well as the proficiency and the fluency in writing, were evaluated by two tests. In the test 10 , the pupils had to write a narrative based on unfinished phrases that could organize freely but also appropriately. In the test 11 , the pupils were asked to write a story based on six images.

The test 12 tested the ability to correct and improve the content of a text. The pupils must write better a telegraphic passage adding their details, describing better the news, and changing the noun phrases into verb phrases. There was the possibility the pupils to focus their efforts on the surface of the passage without changing the noun phrases into verb phrases. Also, there was the possibility they don't interfere with the meaning of the text.

\subsection{Procedure}

To ensure the same level of linguistic and educational support for pupils from their families, the research conducted in 7 schools of neighboring areas at Athens, Zografou, Athens (Goudi) and Kaisariani. The testing process was carried out within school hours with the consent of both the school principal and the class teachers and parents. The conditions of administration varied, and 22 pupils tested individually in a quiet classroom while the 34 pupils tested in their classroom as a group. Group administration performed as a test in the class, and for the needs of this study, we use only tests of pupils with high school performance.

Tests were provided based on a strict protocol with written instructions to the examiners recording the responses to individual assessment brochures. Administration performed in three phases, and it did on different days of the week. The first phase included the punctuation test, the syntax test, and the vocabulary test (40 minutes). The second phase involved the organizing test and the writing test with the help of phrases (40 minutes duration). The third phase included the content improvement test and the writing test with the help of pictures (40 minutes duration). Times respond to most pupils generally, but they have been adapted to the rhythms of each child so as not to affect the performance.

\subsection{Edits Data Collection and Analyses}

According to the international literature, and also concerning the Greek educational reality, the evaluation of the written tests can be spherical rendering a single degree. But also it can be more analytical, discriminating elements of the writing and evaluating each of them individually based on a particular characteristic that defined and based on certain features, three or four. The analytical approach emerged from the need for greater credibility and objectivity in the results of the direct tests. But also for a more detailed analysis of the learners' abilities to inform better who would use the results. Suggested in the case of heterogeneous evaluators and is a modified objective as it guarantees the study and evaluation of all the language skills examined [7].

Many researchers, however, argue that the assessment should be done using both the general impression method and the analytical correction. That is to say put general evaluation criteria such as the content completeness, the relevance of the text (clear words, the validity of the information, organizing) and its effectiveness (achievement of a communication purpose). But that is also to evaluate individual parameters such as the content (relevance of information to the subject, sufficiency of information, originality), the organizing (structure of the text, logical sequence of thoughts, consistency, parsing, punctuation), the vocabulary (variety, correct use of meaning of the words), the style (adaptation to communicative circumstances), the syntax, the spelling-morphology and the clarity-readability of the text. Thus, on the one hand, the overall image of the written paper is not lost, and on the other, the reliability of the written evaluation parameters [5] assured.

By combining the general impression, and the analytical correction method, in the writing tests and the improvement content tests were evaluated individual parameters such as the content completeness, the text relevance, its effectiveness, the organizing, the vocabulary, the style, the syntax, the spelling-morphology, and the text clarity-readability. The total grade of each pupil, the maximum overall performance of 100, arose from the sum of the scores in the product control keys by the informal educational assessment: paragraph, content and productivity, spelling [8].

For the credibility of the graduation, the texts coded, and each text corrected by two evaluators. One was the researcher, who is the author of the article, and the other was a teacher, who did not know the participants. At first, the agreement of the two evaluators was not enough high (59\%), but after resolving disputes, after discussion, it was high (93\%). The 
disagreements were about the divergence between the two graduations, mainly on tests of writing, organizing, and content improvement. To resolve these disagreements, the two evaluators reviewed the texts, and they agreed on a joint new grade.

In the tests with the one-way answers counted the number of errors. The scores of the pupils in the tests resulted from the number of correct answers. In the tests with diversity answers the pupils' responses appreciated, and they got specific units, depending on whether the answers were correct, partially correct, or wrong based on specific criteria mentioned above.

In this study, is used the analysis of variance ANOVA for statistical analysis of the collected data. To find out the performance of pupils when they tested individually and when they tested as a group, a comparison of mean scores adopted to compare the performance of two groups of pupils both in each test and in the individual test criteria. To compare two groups from test to test, their performance calculated in percentages.

Table 1. Comparison of the average performance of two groups of pupils in each test.

\begin{tabular}{|c|c|c|c|c|c|c|c|}
\hline \multirow{2}{*}{ Groups } & \multicolumn{2}{|c|}{ Tested Individually $(\mathrm{N}=22)$} & \multicolumn{2}{|c|}{ Tested as Group $(\mathrm{N}=34)$} & \multirow{2}{*}{ F $(1,55)$} & \multirow{2}{*}{$\mathbf{p}$} & \multirow{2}{*}{$n^{2}$} \\
\hline & M & $\mathbf{S}$ & M & $\mathbf{S}$ & & & \\
\hline Test 1 & 14.49 & 1.740 & 11.64 & 2.840 & 17.830 & 0.0001 & 0.25 \\
\hline Test 2 & 4.00 & 0.000 & 3.50 & 0.492 & 22.540 & 0.0001 & 0.29 \\
\hline Test 3 & 4.00 & 0.000 & 2.55 & 1.341 & 25.228 & 0.0001 & 0.32 \\
\hline Test 4 & 5.09 & 0.629 & 2.38 & 1.348 & 77.421 & 0.0001 & 0.59 \\
\hline Test 5 & 7.86 & 0.467 & 7.05 & 1.594 & 5.281 & 0.025 & 0.09 \\
\hline Test 7 & 7.18 & 1.006 & 5.61 & 1.938 & 12.145 & 0.001 & 0.18 \\
\hline Test 8 & 8.00 & 0.000 & 7.38 & 0.652 & 19.613 & 0.0001 & 0.27 \\
\hline Test 9 & 11.52 & 1.085 & 9.48 & 2.843 & 10.272 & 0.002 & 0.16 \\
\hline Test 10 & 92.09 & 17.171 & 73.35 & 27.534 & 8.115 & 0.006 & 0.13 \\
\hline Test 11 & 83.19 & 19.220 & 67.41 & 27.013 & 5.643 & 0.021 & 0.10 \\
\hline Test 12 & 95.50 & 12.340 & 80.85 & 25.002 & 6.497 & 0.014 & 0.11 \\
\hline
\end{tabular}

\section{Results}

Findings of this study presented in three parts. The first part examines the mean scores of the results in writing tests in each test. The second part examines the pupils' performance from test to test, and the third part examines the differences between the two groups in the individual criteria of writing tests.

\subsection{The Performance of Two Groups in Each Test}

As shown in Table 1, in individual assessment, the pupils had much better performance in all tests with statistically significant differences. Analysis of the ANOVA variance showed a statistically significant effect on the type of assessment $\mathrm{F}(1,55)=10.098, \mathrm{p}<0.001, \mathrm{n} 2=0.74$. A greater effect observed in the tests1 (punctuation), test 2 (simple sentences- active and passive syntax), test 4 (changes to the grammatical types of words), test 6 (completion the second part of proverbs, simulations, and metaphors) and test 8 (definition of words) $(\mathrm{p}<0.001)$. The effect is significant in the other tests, although it differs from test to test and the level of significance is lower.

\subsection{The Performance of Two Groups from Test to Test}

To compare the performance of the two groups of pupils from test to test their performance is presented in percentages (Figure 1). There are differences in performance. But the difficulties in the two groups are similar depending on the type of test. The smallest differentiation observed in individual assessments. In group assessments, the pupils were more struggles to complete similar, opposite, or compound words in the text (test 5). Difficulties also encountered in completing the second part of proverbs, simulations, and metaphors (test 6), in punctuation (test 1), in making compound sentences (test 3 ) and in related words (test 7).

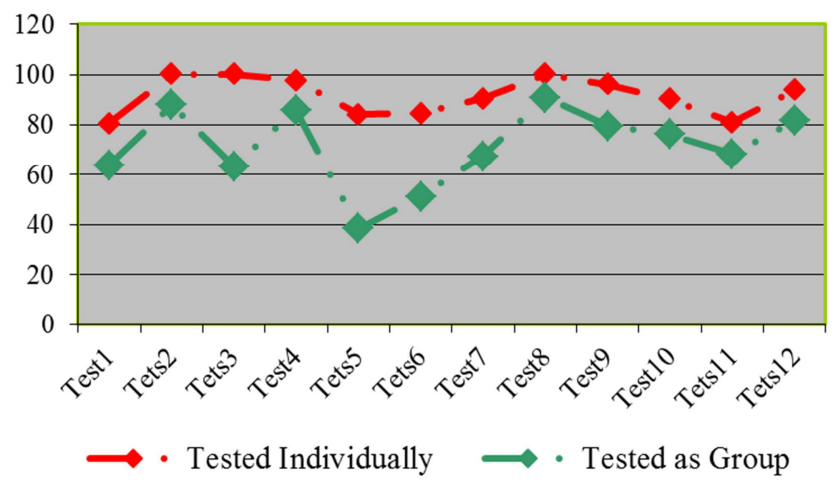

Figure 1. Percentage of performance in all tests for each type of assessment.

In individual assessment, pupils had more difficulties in punctuation (test 1) and in writing tests with images (test 11) with a slight difference from completing similar, opposites, or compound words. They also encountered several difficulties in completing the second part of proverbs, simulations, and metaphors (test 6) and in related words (test 7). In the definition of concepts, all pupils had fewer difficulties. In individual assessment, pupils did not have difficulties in the structure, simple or compound sentences (test 2, test 3). 
Table 2. Comparison of average performance of two groups of pupils in the criteria of the writing texts (test 10, test 11).

\begin{tabular}{|c|c|c|c|c|c|c|c|}
\hline \multirow[b]{2}{*}{ Groups } & \multicolumn{2}{|c|}{ Tested Individually $(\mathrm{N}=\mathbf{2 2})$} & \multicolumn{2}{|c|}{ Tested as Group $(\mathrm{N}=34)$} & \multirow{2}{*}{ F $(\mathbf{1 , 5 5 )}$} & \multirow{2}{*}{$\mathbf{p}$} & \multirow{2}{*}{$\mathbf{n}^{2}$} \\
\hline & M & $\mathbf{S}$ & M & $\mathbf{S}$ & & & \\
\hline Words (Test 10) & 174.86 & 52.963 & 115.85 & 53.261 & 16.468 & 0.0001 & 0.23 \\
\hline Words (Test 11) & 102.90 & 42.532 & 70.76 & 45.089 & 7.092 & 0.010 & 0.12 \\
\hline Sentences (Test 10) & 18.40 & 6.594 & 10.58 & 4.948 & 25.627 & 0.0001 & 0.32 \\
\hline Sentences (Test 11) & 9.90 & 5.060 & 5.79 & 3.400 & 13.285 & 0.001 & 0.20 \\
\hline Words per Sentence (Test 10) & 9.63 & 1.292 & 10.26 & 3.979 & 0.511 & 0.478 & 0.01 \\
\hline Words per Sentence (Test 11) & 11.13 & 2.623 & 11.58 & 4.948 & 0.155 & 0.696 & 0.00 \\
\hline Mistakes (Test 11) & 4.77 & 3.611 & 6.05 & 6.362 & 0.741 & 0.393 & 0.01 \\
\hline Structures (Test 10) & 88.43 & 27.026 & 62.26 & 30.514 & 10.720 & 0.002 & 0.17 \\
\hline Structures (Test 11) & 51.92 & 27.330 & 34.88 & 20.754 & 7.007 & 0.011 & 0.12 \\
\hline Language style (Test 10) & 9.09 & 0.683 & 8.38 & 2.774 & 1.372 & 0.247 & 0.03 \\
\hline Language style (Test 11) & 9.01 & 0.334 & 8.35 & 2.739 & 1.235 & 0.271 & 0.03 \\
\hline Authenticity (Test 10) & 9.77 & 0.528 & 8.76 & 2.995 & 2.427 & 0.125 & 0.04 \\
\hline Authenticity (Test 11) & 9.33 & 0.776 & 8.06 & 2.776 & 4.352 & 0.042 & 0.08 \\
\hline Relevance (Test 11) & 9.27 & 0.810 & 8.06 & 2.776 & 3.976 & 0.051 & 0.07 \\
\hline
\end{tabular}

\subsection{The Performance of Two Groups in the Criteria of Writing Tests}

As shown in Table 2, in individual assessment, the pupils had much better performance in all criteria of both writing tests, except for the number of words per sentence in both tests. By comparing the mean scores, it appears that in group assessment, pupils' texts were smaller with poor vocabulary, and they had poor editorial sentence structure concerning all the sentences, simple and compound.

On the contrary, concerning the number of words per sentence, performance between the two groups did not differ. Also, we found that the spelling mistakes increase in both groups according to the extent of the texts. The difference between the two groups is higher in the writing test with images.

In group assessment, pupils' performance was lower both in the structure of paragraphs, and in the wealth of ideas, the way they organized, and the accuracy of their expression. Analysis of ANOVA variance showed a statistically significant effect on the type of assessment $\mathrm{F}(1,55)=2.767$, $\mathrm{p}=0.004, \mathrm{n} 2=0.67$ and statistically significant differences in significance level $p=0.0001$ were found only for the number of words, and the number of sentences in the writing test with phrases. Significant differences, also, found for the number of words $(p=0.010)$ and sentences $(p=0.001)$ in the writing test with images, for the structure of text both in the writing test with phrases $(p=0.002)$ and in the writing test with images $(p=0.011)$ and for the authenticity in the writing test with images $(p=0.042)$. The other criteria did not show statistically significant differences.

\section{Discussion}

Both from the general impression, and the analytical assessment of pupils' performance, it appears that the tests were easy to use and could be performed satisfactorily by all the age groups that participated in the study. The findings of this study show that pupils in the last grades of primary school have a lot of difficulties and especially in the relations of words and understanding of special meanings like the idioms, the proverbs and the metaphorical style of the words. All pupils encountered great difficulties in producing compound words and using them in phrases correctly, as well as in using synonyms or opposite's concepts. Also, they had many problems in completing incomplete clauses of proverbs, simulations, and metaphors and producing related words based on their semantic relations. These results agree with Nikolopoulos's findings [12] for the difficulties of the pupils of the last grades of primary school in the connection of concepts of synonyms or opposites. As well as with finds for problems in processing messages at a non-literal level [13]. It can see that the development of the meaning of the word is a complicated process, depending to a large extent on the general cognitive development of children [6].

In agreement with other reports, we found that pupils in the last grades of primary school do not have difficulty in defining words, and they understand more words than they use in their linguistic acts [10]. They also do not appear to have any particular difficulty in understanding the syntactic function of words and their syntactic relationships. They recognize their various morphological types, and they can use them in phrases and sentences to identify their grammatical function and their suitability. They can perceive the sequence of events, and they can improve a text by intervening in its meaning.

The assessment process, individual vs. group, seems to have influenced the pupil's performance significantly. In group assessment, the pupils' performance in all tests was lower. These findings are consistent with the view that the individual tested focuses better on individual skills, and it enables the examiner to gain a more valid image of the behavior of the subject [2]. More important was the influence on the application of punctuation rules and the understanding of the syntactic function of words, and the structure of sentences. Equally important was the influence on the complementing of various morphological types of words, as 
well as on the understanding of the specific meanings of words and the metaphorical style. Apparently, in these tests, the direct examiner's contact with pupils during the individual assessment haven helped them to focus on their skills and to perform better. The influence was smaller on the production, organizing, and improvement of texts by pupils, on recognition of synonymy, opposite, production and synthesis relations, and knowledge of the meaning of a word and the interpretation of its multiple meanings. It seems that, in these tests, the pupils' response behavior is more independents, and they require less immediate intervention by the examiner.

Regarding the ability of the tests, it appears that they have highlighted, and they describe the deficits and skills of pupils of the last three grades of primary school in the processing and production of written discourse adequately. But it should not forget that each test has a limited degree of reliability, smaller or larger. It should also bear in mind that the assessment provides a sampling of a child's performance that may differ from his or her actual image. However, the separation of the assessment process, individual vs. group, highlights an issue that has not studied in Greece. The present research may be a reason for further research concerning both the importance of the teacher in the assessment process of a pupil by constructing himself/herself curriculum-based tools based on his/her knowledge and experience as well as the assessment process itself.

\section{References}

[1] Almond, R. J. (2009). Group assessment: Comparing group and individual undergraduate module marks. Assessment \& Evaluation in Higher Education, 34 (2), 141-148.

[2] Vicki, A., \& Papanis, E. (2007). Diagnostic Tools For Teachers. Greek Social Research. Retrieved on January 25, 2018, from http://epapanis.blogspot.com/2007/11/blogpost.html.

[3] Georgas, D. D., Paraskevopoulos, I. N., Bezevegis, H. G., \& Giannitsas, N. D. (1997). Greek WISC-III: Wechsler Intelligence Scales for Children. Athens: Greek Letters.

[4] Dimakos, I. (2015). Alternative assessment of elementary school students' written skills. In: M. Vlasopoulou, A. Giannettopoulou, M. Diamanti, L. Kirpotin, E. Levadi, K. Lefteri \& G. Sakellariou (Eds.), Language Difficulties and Writing in School Learning Framework (pp. 154-163). Athens: Gregory.

[5] Operational Program "Education \& Lifelong Learning" (2011). Curriculum for Teaching Modern Greek Language in Compulsory Education (Elementary\&High School)-Teacher's Guide. Athens: NSRF 2007-13/Education and Lifelong Learning Operational Program $\backslash$ Curriculum 1-2-3 'NEW SCHOOL (21st Century School)-New Curriculum, Horizontal Practice' MIS: 295450. Retrieved on December 10, 2017, from

http://www.moec.gov.cy/dde/diapolitismiki/ilektroniko_yliko/ odigos_glossas_gia_dimotiko_gymnasio.pdf.

[6] Fenson, L., Dale, P. S., Reznick, J. S., Bates, E., Thai, O. J., \&
Pettnick, S. J. (1994). Variability in early communicative development. Monographs of the Society for Research in Child Development, 59, 1-173.

[7] Iliopoulou, K. (2009). Assessment of Written Production in Secondary Education. Analytical versus Holistic approach: a comparative approach. Retrieved on October 20, 2017, from http://ipeir.pde.sch.gr/educonf/2/06DefterovathmiaEkpedefsi/i liopoulou/iliopoulou.pdf.

[8] Kyriazis, O., \& Spandidakis, I. (2001). Ways of assessing the difficulties of writing and writing and the social difficulties of primary school students. Motivational Science Review, 3, 3578.

[9] McAfee, O., Leong, J. D., \& Bodrova, E. (2016). Assessing and Guiding Young Children's Development and Learning $\left(6^{\text {th }}\right.$ ed). Publisher: Person.

[10] Melka, F. (1997). Receptive vs. productive aspects of vocabulary. In N. Schmitt \& M. McCarthy (Eds.), Vocabulary: Description, Acquisition, and Pedagogy (pp. 84-102). Cambridge: Cambridge University Press.

[11] Mouzaki, A. (2010a). Spelling skill assessment. In: A. Mouzaki \& A. Protopapas (Ed.), Spelling: Learning and Disorders (pp. 307-325). Athens: Gutenberg.

[12] Nikolopoulos, D. (ed.) (2008). Language development and disorders (pp. 231-276). Athens: Topos.

[13] Nippold, M. A. (2016). Later Language Development: Schoolage children, adolescents, and young adults (4th edition). Austin, TX: Pro-Ed.

[14] Panteliadou, S., \& Patsiodimou, A. (2007). Teaching assessment applications and learning difficulties. Volos: Graph.

[15] Papoutsakis, K., Gougoumi, M., Grymanis, I., Zachari, S., Salkatra T., \& Tsiga, K. (2016, June). An informative evaluation tool for learning difficulties. An announcement at the 6th Panhellenic conference of science education and special education. Athens. DOI: http://dx.doi.org/10.12681/edusc.998.

[16] Porpodas, K., Diakogiorgi, K., Dimakos, I., Karantzis, I., Paleododoros, A., Yfanti, K., Tsangari, G., \& Karabetsou, M. (2007). Diagnostic Tool for Difficulties in the Writing of Pupils in C-F grade of Primary School. Ministry of Education - EPEAEK (2). Printezi, A., \& Polychronis, F. (2016). Coping with difficulties in writing. Pedagogical Reason, 1, 153-174. Retrieved on November 6, 2018, from https://www.plogos.gr/TEYXH/2016/8.pdf.

[17] Printezi, A., \& Polychronis, F. (2016). Coping with difficulties in writing. Pedagogical Reason, 1, 153-174. Retrieved on November 6, 2018, from https://www.plogos.gr/TEYXH/2016/8.pdf.

[18] Sakellariou, G. (2007). Assessing the written language difficulties of children and adolescents as part of an expanded process of approaching the subject in clinical speech therapy practice. In: M. Vlasopoulou, A. Giannettopoulou, M. Diamanti, L. Kirpotin, E. Levadi, K. Lefteri \& G. Sakellariou (Eds.), Language Difficulties and Written Speech in School Learning Framework (pp. 68-82). Athens: Gregory.

[19] Salvia, J., Ysseldyke, J., \& Witmer, S. (2012). Assessment: In special and inclusive education. Cengage Learning. 
[20] Spandidakis, I. (2011). Problems in the production of the writing of school-age children: Identification-EvaluationCoping. Athens: Field.

[21] Spandidakis, I. (2005). Written Problems. A proposal in the framework of the program: "Training and specialization of general education teachers and executives (with emphasis on preschool and primary teachers) for students with speech and speech problems". Retrieved on January 15, 2017, from http://repository.edulll.gr/edull1/retrieve/3634/1072.pdf

[22] Tzivinikou, S. (2018). Evaluate, Design, Teach: Effective reading and writing interventions for students with learning and other difficulties. Thessaloniki: A. Stergiou.
[23] Tzouriadou, M., Sygolitou, E., Anagnostopoulou, E., \& Vakola, I. (2008). Psychometric Criterion of Language Proficiency L-a-T-o. Thessaloniki.

[24] Ministry of National Education and Religious Affairs Pedagogical Institute. (2007). New School Textbooks Language E \& F Elementary. Athens: Pedagogical Institute Organization for the Publishing of Textbooks. Retrieved on September 20, 2017, from www.pi-schools.gr.

[25] Ministry of National Education and Religious Affairs Pedagogical Institute (2003). A Cross Thematic Curriculum Framework for Compulsory Education Diathematikon Programma. Athens: Pedagogical Institute. Retrieved on September 20, 2017, from www.pi-schools.gr. 